\title{
Time-Economic Lifetime Assessment for High Performance Thermal Barrier Coating Systems
}

\author{
Marion Bartsch \\ Linder Hoehe, amarion.bartsch@dlr.de \\ Bernd Baufeld \\ Katholieke Universiteit Leuven \\ S. Dalkilic \\ Anadolu University \\ Iulian Mircea \\ German Aerospace Center \\ K. Lambrinou \\ Katholieke Universiteit Leuven
}

See next page for additional authors

Follow this and additional works at: https://engagedscholarship.csuohio.edu/enme_facpub

Part of the Engineering Science and Materials Commons, and the Mechanical Engineering Commons How does access to this work benefit you? Let us know!

\section{Original Citation}

Bartsch, M., Baufeld, B., Dalkili, S., Mircea, I., Lambrinou, K., Leist, T., Yan, J., Karlsson, A. M., 2007, "TimeEconomic Lifetime Assessment for High Performance Thermal Barrier Coating Systems," Key Engineering Materials, 333, pp. 147-154.

This Article is brought to you for free and open access by the Mechanical Engineering Department at EngagedScholarship@CSU. It has been accepted for inclusion in Mechanical Engineering Faculty Publications by an authorized administrator of EngagedScholarship@CSU. For more information, please contact library.es@csuohio.edu. 


\section{Authors}

Marion Bartsch, Bernd Baufeld, S. Dalkilic, Iulian Mircea, K. Lambrinou, T. Leist, J. Yan, and Anette M. Karlsson 


\title{
Time-Economic Lifetime Assessment for high Performance Thermal Barrier Coating Systems
}

\author{
M. Bartsch ${ }^{1, a}$, B. Baufeld ${ }^{2, b}$, S. Dalkilic ${ }^{3}$, I. Mircea ${ }^{1}$, K. Lambrinou $^{2}$, T. Leist ${ }^{4}$, \\ J. Yan ${ }^{5}$, A.M. Karlsson ${ }^{5, c}$ \\ ${ }^{1}$ Institute of Materials Research, German Aerospace Center, Linder Hoehe, D-51147 Cologne, \\ Germany \\ ${ }^{2}$ Department of Metallurgy and Materials Engineering, Katholieke Universiteit Leuven, Kasteelpark \\ Arenberg 44, 3001 Heverlee, Belgium \\ ${ }^{3}$ College of Aviation, Anadolu University, 26470 Eskisehir, Turkey \\ ${ }^{4}$ Material- and Geo-Sciences, Darmstadt University of Technology, Petersenstr. 23, D-64287 \\ Darmstadt, Germany \\ ${ }^{5}$ Department of Mechanical Engineering, University of Delaware, 19716 Newark, DE, USA \\ amarion.bartsch@dlr.de, bbernd.baufeld@mtm.kuleuven.be, ckarlsson@udel.edu
}

Keywords: Lifetime Assessment, Thermal Barrier Coating, Accelerated Testing, Damage

Parameter.

\begin{abstract}
Strategies for tim e-economic lifetime assessm ent of therm al barrier coatings (TBC) in service are described and discussed on the basis of experim ental results, achieved on $\mathrm{m}$ aterial systems with coatings applied by electron beam physical vapour deposition. Service cycles for gas turbine blades have been sim ulated on specim ens in thermo-mechanical fatigue tests, accelerating the fatigue processes by an increase of load fre quency. Time dependent changes in the $\mathrm{m}$ aterial system were imposed by a separate ageing, where the samples were pre-oxidized prior to the fatigue test. Results of thermo-mechanical fatigue tests on pre-aged and as-coated specimens gave evidence of interaction between fatigue and ageing processe $\mathrm{s}$. An alternative approach is used, which is focused on the evolution of a failure relevant dam age parameter in the TBC system. The interfacial fracture toughness was selected as a dam age parameter, since one im portant failure mode of TBCs is the spallation near the interface between th e $m$ etal and the ceram ic. Fracture $m$ echanical experiments based on indentation $m$ ethods have been evaluated for monitoring the evolution of the interfacial fracture toughness as a function of ageing time. It was found that the test results were influenced by both changes of the interface (which is critical in service) and changes in the
\end{abstract} surrounding material.

\section{Introduction}

Thermal barrier coating (TBC) system s are used in the hot gas path of gas turbines, e.g. on turbine blades. Components like turbine blades, especially for aero engines, have to sustain therm al and mechanical cycling but also up to $10,000 \mathrm{~h}$ at high temperature. Thus, a lifetime assessment of TBC systems has to consider changes of the $m$ aterial properties during service due to tim e and temperature depending processes, along with dam age accumulation due to fatigue. Considering the long time of service, realistic 'real tim e' testing is not economical. In the case of pure (m echanical) fatigue, tests can be accelerated to cover $m$ any cycles by increasing the load frequency. Moreover, it is an established $\mathrm{m}$ ethod to accelerate pro cesses depending on tim e-at-high-temperature by increasing the test tem perature. However, at hi gher tem peratures different $\mathrm{m}$ echanisms $\mathrm{m}$ ay be triggered, e.g. other oxidation products may form. Nevertheless, limited but reasonable reduction of test tim e can be achieved. For the case when the fatigue and tim e dependent processes are dependent on each other (i.e. form ation and growth of fatigue damages are influenced by the status achieved by time dependent changes in the $\mathrm{m}$ aterial), acceleration of the laboratory tests $\mathrm{m}$ ay give 
misleading results. An alternative strategy to obt ain accelerated testing is to $\mathrm{m}$ onitor a failurerelevant dam age param eter in realistic cyclic e xperiments and extrapolating the evolution of the damage parameter from interrupted experiments long time before failure occurs.

We will here review two prom ising test $\mathrm{m}$ ethods for developing tim e-economic lifetim e assessments for high performance TBC systems.

\section{Accelerated close to reality testing - Thermal Gradient Mechanical Fatigue}

Specimens. Hollow, dog bone shaped, coated specim ens with an inner diam eter of $4 \mathrm{~m} \mathrm{~m}$ and an outer diameter of $8.6 \mathrm{~m} \mathrm{~m}$ were used for the therm o-mechanical fatigue tests. The substrate was a nickel-based super-alloy IN 100 DS, which was di rectionally solidified (DS) with the $<100>$ direction approximately in the axial specimen direction, in order to simulate the elastic behaviour of single crystal materials used in turbine blades. Th e elastic modulus in the axial direction of IN100 DS was $\mathrm{m}$ easured under tensile load with a hi gh tem perature extensom eter and displays a distribution with values between 117 and $138 \mathrm{GPa}$ at room temperature and between 72 and $83 \mathrm{GPa}$ at $950^{\circ} \mathrm{C}$. The coating system comprises a m etallic oxidation protection layer, the so-called bond coat (BC), and a ceram ic top coat. Both coati ngs were applied by electron beam physical vapour deposition (EB-PVD). The $\mathrm{BC}$ is a NiCoCrAlY with the standard com position in wt \%: $20 \mathrm{Co}$, $21 \mathrm{Cr}, 12 \mathrm{Al}, 0.15 \mathrm{Y}$, balance $\mathrm{Ni}$, and the top coat is pa rtially stabilized zirconia with $7-8 \mathrm{wt} \% \mathrm{yttria}$ (PYSZ). The thickness of the BC is about $120 \mu \mathrm{m} \quad$ and of the ceram ic top coat about $220 \mu \mathrm{m}$. During the coating procedure, a $0.3 \mu \mathrm{m}$ thick alum ina scale, the so-called therm ally grown oxide (TGO), forms between the BC and the ceram ic top coat. The TGO growth entails the form ation of an Al-depleted zone in the adjacent BC. All $\mathrm{m}$ aterials were processed at the Germ an Aerospace Center in Cologne. Part of the specim ens was pre-aged in a separate furnace in air before therm omechanical testing, in order to econom ically accumulate tim e at high tem perature. The heat treatment was cyclic, with each cycle for about $24 \mathrm{~h}$ at high temperature, accumulating 250 and 500 $\mathrm{h}$ at high tem perature, respectively. Cooling down to am bient tem perature was achieved by removing the specimen from the furnace.

Test procedure. The specim ens were subjected to sim ultaneous thermal and m echanical cycling. The mechanical load was applied by a servo-hydraulic testing $\mathrm{m}$ achine, which allowed very fast changes of the load level during the cycling. Th e therm al load was im posed using a radiation furnace powered by quartz lamps. High cooling rates were achieved with an active air cooling from vents in a shutter, which was introduced into the furnace by a pneum atic device. The high heating and cooling rates made it possible to simulate the thermo-mechanical fatigue load of an entire flight of a turbine blade in an aero engine within $3 \mathrm{~m}$ inutes. A detailed description of the testing set up is given in [1]. Thermal cycles were between 100 and $1000^{\circ} \mathrm{C}$, the mechanical load was tensile and in phase. A typical test cycle is displayed in Fig. 1.

During fatigue testing, the specimen was internally cooled by a constant airflow of 45 norm litres per minute. The inlet tem perature of the internal cooling air was about $270^{\circ} \mathrm{C}$. Internal cooling and external heating and cooling, respectively, generate $d$ thermal gradients over the cross section of the specimen. The tem perature difference between the outer and the inner surface was $m$ easured at a calibration specim en with sheet therm ocouples. U nder the quasi-stationary conditions during the high temperature sequence of the test cycle, a te mperature difference between the inner and outer surface of about $170^{\circ} \mathrm{C}$ was $\mathrm{m}$ easured. Because of th e thermal gradient, the test is called therm al gradient $\mathrm{m}$ echanical fatigue (TGMF), in contra st to conventional therm o-mechanical fatigue (TMF). 


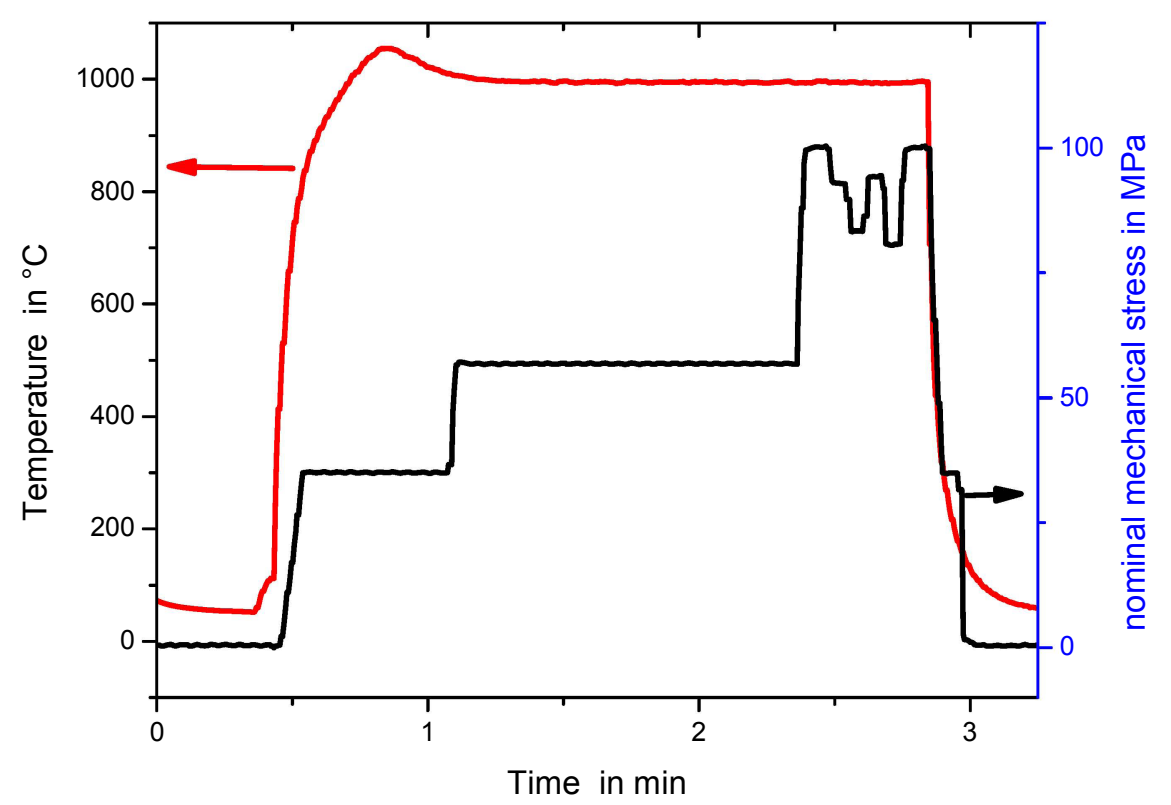

Fig. 1. Typical TGMF cycle with the temperature and the nominal mechanical load profile related to the cross section

Results. Coated specim ens, which were pre-aged for $250 \mathrm{~h}$ or longer at $1000^{\circ} \mathrm{C}$, showed final failure of the TBC system by spallation of the top coat after about 1000 cycles with a nom inal maximal mechanical stress of $100 \mathrm{MPa}$ during TGMF. Specimens in the "as-coated" condition have been cycled for even longer tim es and with higher mechanical loads, but did not show spallation of the ceram ic coating [2]. The spallation has been associated to fatigue cracks, which propagated underneath the TGO, parallel to the surface in the axial and circum ferential directions [3]. The cracks, which resem ble in length sections in thei $r$ mature state a 'sm iley face', always display a crack in the TGO perpendicular to the $m$ echanical load. Fig. 2 gives a schem atic of the 'sm iley crack' feature and Fig. 3 shows the scanning electron microscope (SEM) image of the crack, which motivated the name 'smiley crack'.

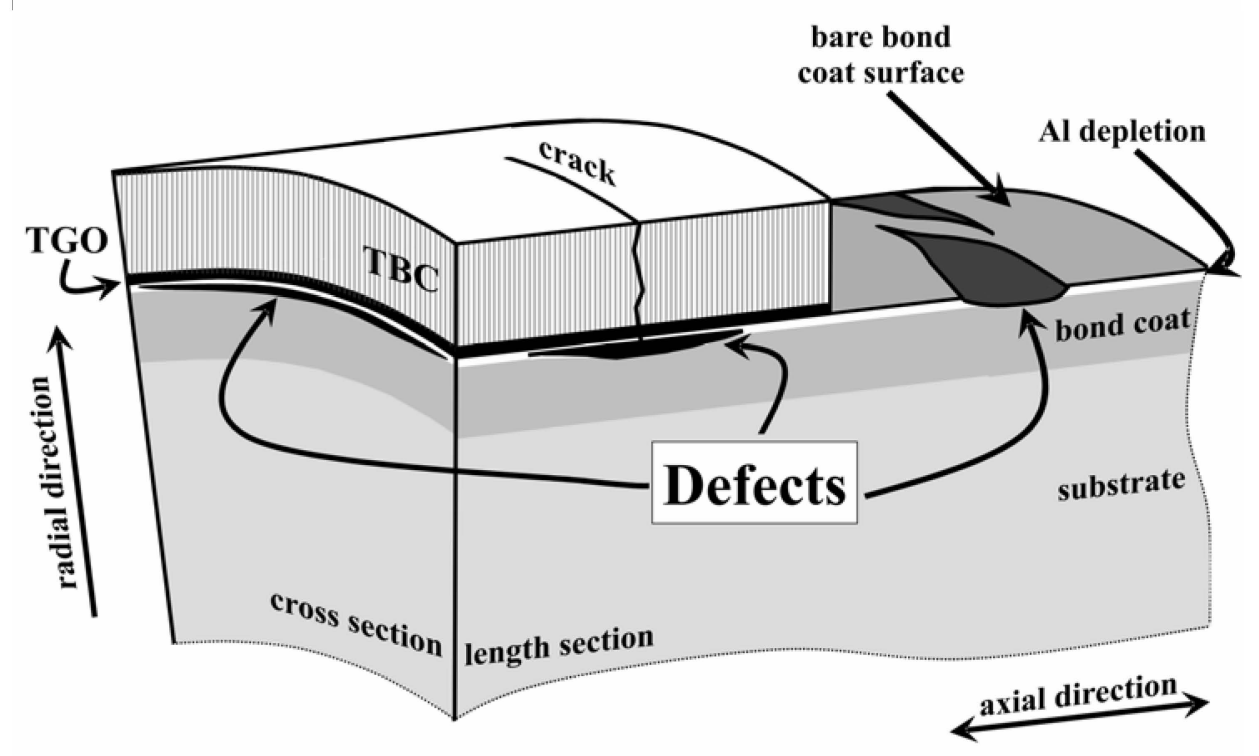

Fig. 2. Sketch, showing the $\mathrm{m}$ ain features of th e observed 'sm iley cracks' in relation to the specimen geometry 


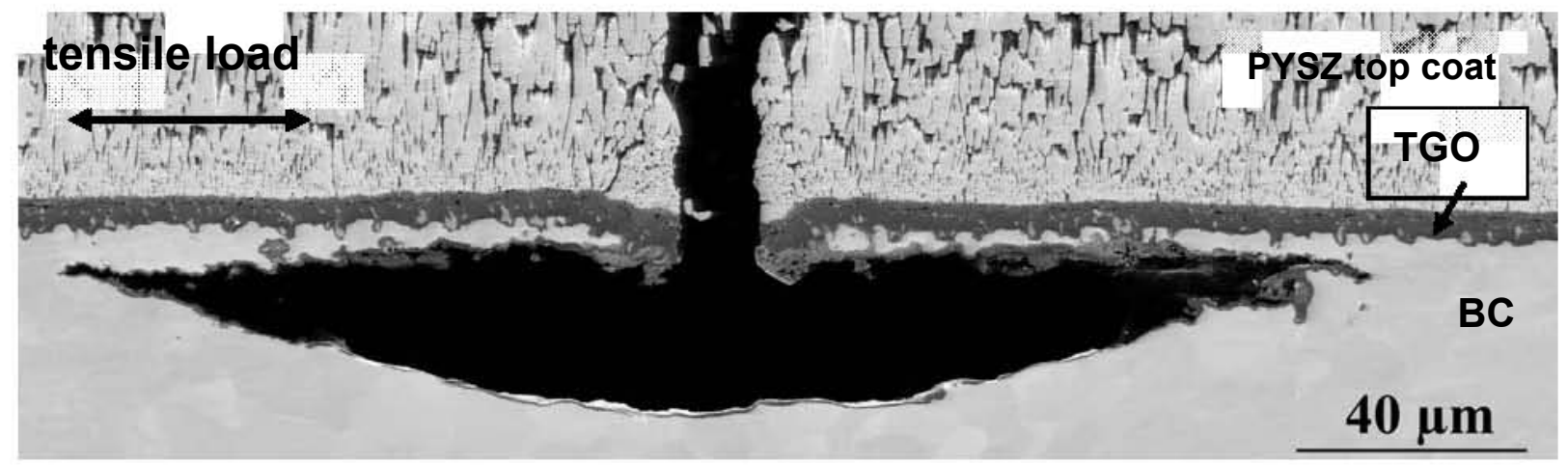

Fig. 3. SEM image of a typical 'smiley crack' prepared by length sectioning

Discussion. Key to the understanding of the 'sm iley crack' evolution is the stress situation in the TGO during TGMF-cycling. The SEM im ages indicate that (in at least one sequence of the TGMF cycle) the tensile stresses in the TGO $\mathrm{m}$ ust ha ve exceeded the TGO strength otherwise a crack through the TGO perpendicular to the mechanical load would not appear. Once the TGO is cracked, oxygen can access the $\mathrm{m}$ etallic $\mathrm{BC}$ and weaken the material by local oxidation and an oxidation assisted fatigue crack is likely to grow. However, linear elastic calculations of the stress distribution across the wall of the coated specim en indicate com pressive stresses in the TGO for the case of a nominal maximal mechanical stress of $100 \mathrm{MPa}$ [2 ]. Looking for inelastic phenom ena, which may entail tensile stresses in the TGO, we found (thr ough SEM analysis) that the IN 100 DS substrate shows significant rafting [3]. However, assum ing linear elastic TGO in the num erical simulations, the accumulation of inelastic strain in the substrat e would develop tensile stresses, not only in the pre-aged but in the as-coated specim ens as well. Since the as-coated specim en was loaded during part of the experim ent with even higher $m$ aximum tensile forces $(2182$ cycles with $m$ aximal nominal tensile stress of $280 \mathrm{MPa}$ ), TGO cracks shoul $\mathrm{d}$ be more likely to occur in these specim ens but were not observed. Thus, the pre-ageing, which results in top coat sintering, TGO growth, and diffusion processes, changes the response of the sy stem. As described by seve ral authors $[4,5]$ and observed here (Fig. 5), the TGO in the as-c oated condition has an interm ixed (mainly $\mathrm{Al}_{2} \mathrm{O}_{3}$ and $\mathrm{ZrO}_{2}$ ), very fine grained morphology with grain sizes of less than $100 \mathrm{~nm}$. During high temperature exposure the TGO grows and form $\mathrm{s}$ a dense zone ( $\mathrm{m}$ ainly $\alpha-\mathrm{Al}_{2} \mathrm{O}_{3}$ ) with grain sizes of $\mathrm{m}$ ore than $1 \mu \mathrm{m}$. Following calculations by Rösler et al. [6], the TGO can relax its stresses at high temperature due to creep processes that depend on the TGO grai $\mathrm{n}$ size, resulting in relaxation tim es for the ascoated TGO at $1000^{\circ} \mathrm{C}$ of less than 1 second and for the dense TGO of more than 10 seconds. In the investigated TGMF cycle, both the ' $m$ ixed zone' and the dense TGO, should be able to relax $m$ ost of the compressive stresses (induced due to the co mbination of thermal gradient, growth stress and thermal property $\mathrm{m}$ ismatch) during the first $2 \mathrm{~m}$ inutes of the cycle (before a fast mechanical load step follows). The increm ental m echanical load st ep imposed in the end of the load cycle takes about 5 seconds. Therefore, there $m$ ay be sufficient time for the fine-grained ' $m$ ixed zone' TGO to relax but not for the evolved 'dense zone' TGO, introducing higher tensile stress in the aged samples. This is currently being investigated and will be published at a later state [7].

\section{Extrapolation of damage parameters - determination of interfacial fracture toughness}

Test method. Among several proposed m ethods for determ ining the interfacial fracture toughness of EB-PVD TBC system s, the Rockwell indentation te st with a conical brale C indenter has been selected. This test $\mathrm{m}$ ethod has som e advantages: in principle it can be applied on specim ens and components of any geometry, requiring only a small quantity of material. Indentation of the coating perpendicular to the interface using a brale C Rockwell indenter was analyzed by Drory and 
Hutchinson [8] and applied on EB-PVD TBCs by Vasi nonta and Beuth [9]. In this test m ethod, the indenter penetrates the coating perpendicular to the surface and generates plastic and elastic deformations in the substrate, which are a driving force for the form ation of delamination cracks at the interface between coating and substrate. E xperiments on system s with a $100 \mu \mathrm{m}$ thick TBC resulted in circular, concentric debonding and buck ling of the coating behind the crack front [9]. The interfacial fracture toughness is estim ated from the calculated in-plane deform ation of the substrate and the $\mathrm{m}$ easured radii of both the $\mathrm{i}$ ndent and the delam ination crack. So far, the mechanics of the Rockwell indentation test is an alyzed for flat specim ens, presum ing isotropic material properties and neglecting the interaction between ceram ic topcoat and the indenter during the indentation process.

Experimental Procedure. Rockwell indentation tests were perform ed on flat specim ens comprising a $4 \mathrm{~m} \mathrm{~m}$ thick isotropic IN 625 substr ate, coated by EB-PVD first with a $100 \mu \mathrm{m}$ NiCoCrAlY bond coat and subsequently with a $280 \quad \mu \mathrm{m}$ thick zirconia layer with $7-8 \mathrm{wt} \%$ yttria (YSZ). The chem ical composition of the coating la yers was the sam e as for the fatigue specim ens described above. The $\mathrm{m}$ aterial system was inves tigated in as-coated condition and after heat treatments of 50,100,200, and $400 \mathrm{~h}$ at $1000^{\circ} \mathrm{C}$ in air. The indentation was perform ed using an electromechanical testing machine. The displacem ent of the indenter was $r$ ecorded by means of an inductive displacement transducer; the load was record ed by means of a load cell. Test series with indentation loads from 50 to $1000 \mathrm{~N}$ were conducte $\mathrm{d}$ on the specimens. After the indentation, cross sections of the tested specim ens at the im print of the indenter were prepared and investigated by optical microscopy and SEM. The length of the gene rated crack system at the interface or parallel to the interface was measured, and the crack paths have been evaluated.

Results. The length of the crack system $\mathrm{s}$ is a function of the applied load, i.e. higher loads give longer cracks. Comparing as-coated and pre-aged specimens, the same load resulted in longer crack systems for the as-coated specimens (Fig. 4).

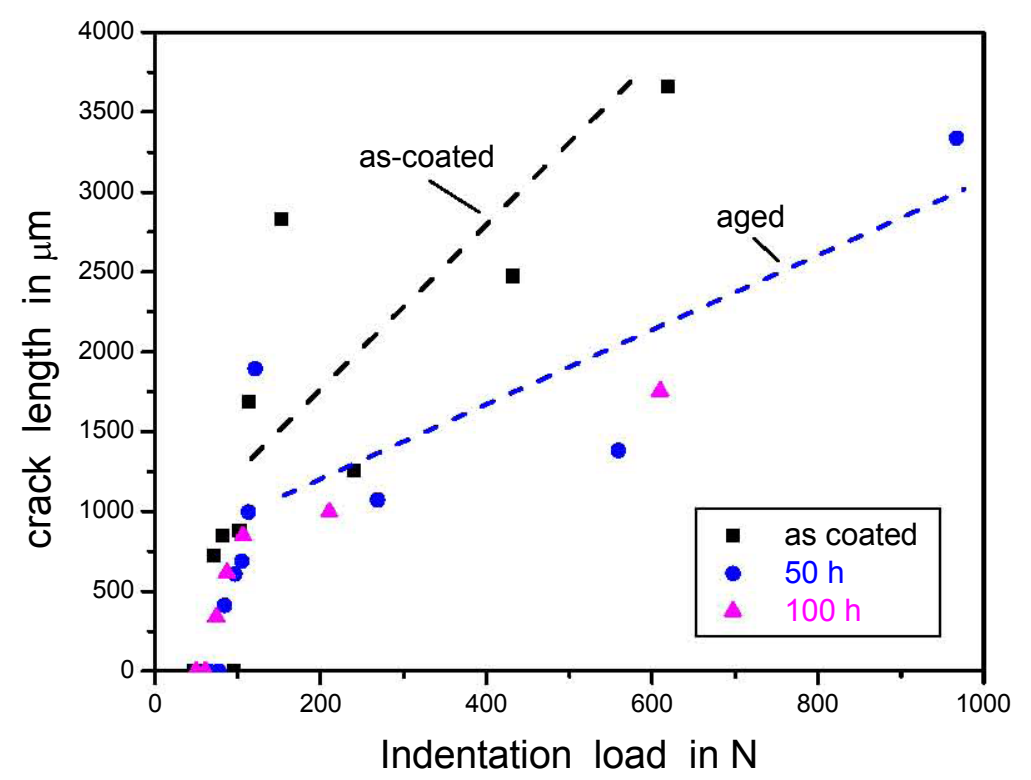

Fig. 4. Crack length as function of indentation load for TBC systems in both as-coated and aged condition

Specimens aged for $400 \mathrm{~h}$ showed delayed but s pontaneous spallation of the ceram ic top coat after removing from the furnace. This phenom enon has been often observed, and it is identified as 
stress corrosion cracking [10]; it is also nicknamed 'desk-top effect' since it often happens when the specimen is laid on the 'desk top' after the com pletion of therm al exposure experim ents. Thus, it was not possible to perform indentation tests on $400 \mathrm{~h}$ aged specimens. Moreover, after indentation of the $200 \mathrm{~h}$ aged sample, delayed spallation of the top coat occurred starting from the free edges of the flat specim ens. However, it was possible to prep are cross sections of som e of these indented specimens for further microscopic investigations.

Analysis of the crack path revealed that in the as-coated condition the crack system propagated mainly at the interface between TGO and BC. Afte $\mathrm{r} 50 \mathrm{~h}$ of therm al treatment the crack path was partially along the interface between $\mathrm{TGO}$ and $\mathrm{BC}$, but mainly parallel to th is interface within the TGO and near to this interface within the top co at. With increasing ageing time, the crack system $\mathrm{s}$ remained within both the top coat and the TGO, ne ver penetrating the dense zone of the TGO. The characteristics of the crack path are illustrated in Fig. 5.

As coated
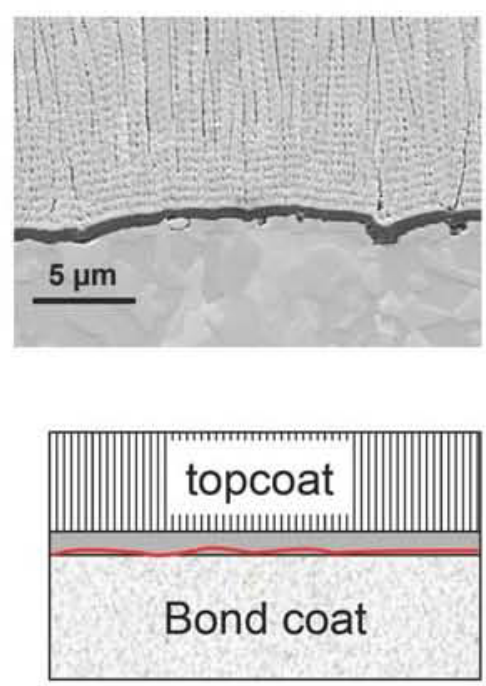

$50 \mathrm{~h}$
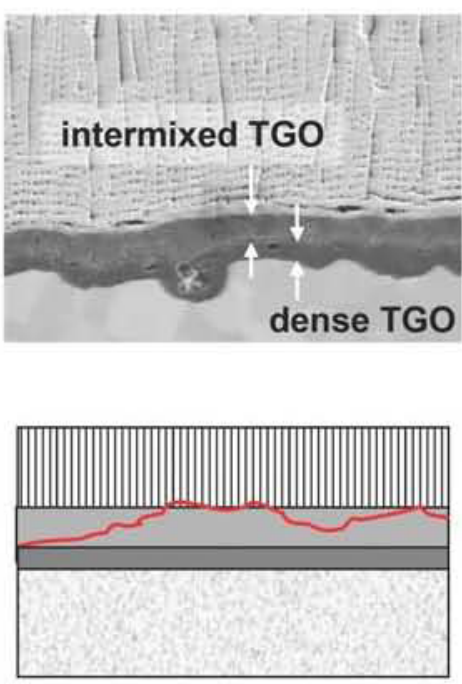

$200 \mathrm{~h}$
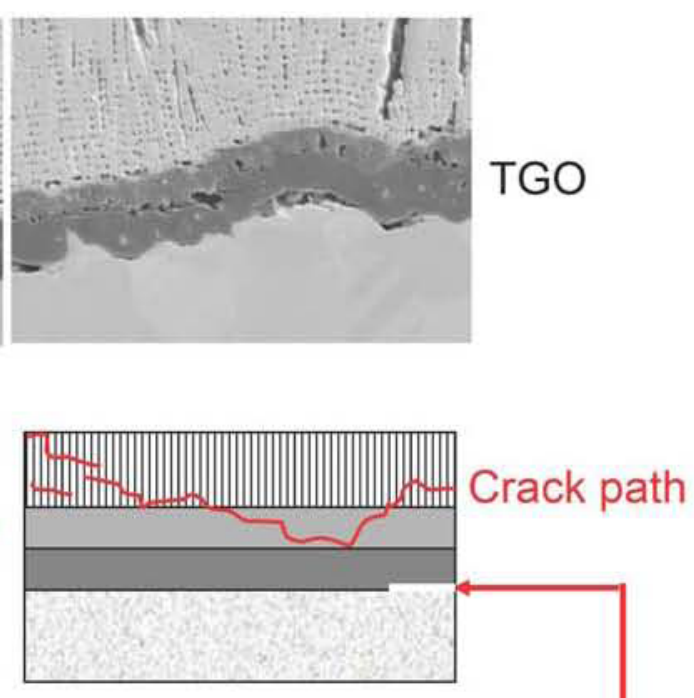

Beginning stress corrosion cracking from the specimen edges, 'desk top effect'

Fig. 5. SEM im ages displaying the changes of the interfacial region due to ageing, especially the growth of the TGO with a light grey interm ixed zone next to the top coat and a darker dense zone, separated from the interm ixed zone by a line of pores. The schem atics show the respective crack path after indentation.

Discussion. Rockwell indentation tests perform ed on th e TBC surface resulted in crack system s propagating at or parallel to the interface be tween the TGO and the $\mathrm{BC}$. Given a constant indentation load, the length of these crack system s is shorter after ageing compared to the as-coated condition. Applying the equations given in [9 ], the experim ents would result in an increase of the interfacial fracture toughness of the coating system due to ageing at high tem peratures, which is in contradiction to the observed coating behaviour in thermal and thermo-mechanical tests as well as in service. Usually, failure of the TBC occurs by spallation of the top coat at the interf ace between the $\mathrm{BC}$ and the $\mathrm{TBC}$. Long-term aged specim ens of this test series showed delayed, spontaneous spallation at the TGO-BC interface as well. Exam ination of the crack paths reveals that the crack 
systems propagate along different paths in the as-coated and the aged condition. In the aged condition the indentation-induced cracks did not pene trate the TGO but were either trapped in the ceramic top coat or within the TGO at a porous line that form $\mathrm{s}$ between the $\mathrm{m}$ ixed zone and the dense zone during long-term ageing. Thus, in ag ed specimens the indentation-initiated cracks do not reach the weakest interface. In particular, it a ppears that the dense zone of the TGO is strong enough, com pared to the $\mathrm{m}$ ixed zone and the top co at, and that it shields the weaker interface between the BC and the dense zone of the TGO. Sin ce the top coat material has gained in hardness and strength during the time at high temperature due to sintering processes, the cracks needed more energy for propagation. Thus, the crack system s in aged specimens are shorter than in the as-coated condition, and they are not a measure of the fracture toughness of the decisive interface.

\section{Concluding remarks}

Strategies are needed to reduce the test tim e for reliable lifetim e assessm ent of com ponents that have to survive long term service. For exam ple, it is im practical to perform realistic therm omechanical fatigue tests for turbine blade materials in real time until failure, if the blade or the TBC system on the blade is supposed to function 5,000 to 10,000 flights of 1 to $10 \mathrm{~h}$. In this paper, we discuss two test methods designed to achieve this goal.

Strategies for test-acceleration have been applied on EB-PVD TBC system s, i.e. therm omechanical fatigue has been accelerated by high lo ading rates as well as high heating and cooling rates. Operating tim e in the f atigue testing facility has been reduced by pre-ageing the specim ens separately. The resulting dam age features in the pr e-aged specimens were significantly different to those in the as-coated specimens. A specific type of fatigue cracks, the 'smiley cracks,' with a TGO crack perpendicular to the $m$ echanical tensile lo ad, evolved only in pre-aged specim ens. The preaged samples had form ed a coarse-grained, dense TGO, which was not present in the 'as-coated' samples. The analysis of the results suggests that the loading rate was too high to allow relaxation processes in the dense TGO of pre-aged specim ens but allowed relaxation in the thin $f$ ine-grained TGO of the as-coated specimens. Thus, tensile stresses develop only in the pre-aged TGO, entailing fracture of the TGO. For lifetim e assessment of the TBC system in service, this result showed how important it is to keep the acceleration of tests $\mathrm{w}$ ithin limits, which ensure that damage mechanisms in testing are the same as in service.

Experiments have been perform ed pursuing an alternative acceleration-strategy, $\mathrm{m}$ onitoring a failure-relevant dam age param eter and extrapolati ng its evolution from interrupted experim ents, long time before failure occurs. In this study, th e interfacial fracture toughness of the TBC system was selected and the experim ent involved the Rock well brale $\mathrm{C}$ indentation of the surface of both as-coated and aged specim ens. It was found that the results were not governed by changes of the interface between BC and TGO (which is critical in se rvice) but by the sintering of the top coat and the growth of a dense TGO, which shielded the weakest interface from indentation-induced cracks. This example shows how important it is to capture with the selected experiment the evolution of the critical feature, which determines the lifetime of the material system in service.

\section{Acknowledgement}

The work is supported in part by the European Com munity's Hum an Potential Program under contract HPRN-CT-2002-00203, [SICMAC]. I. Mircea and K. Lam brinou acknowledge the financial support provided through the European Com munity's Hum an Potential Program under contract HPRN-CT-2002-00203, [SICMAC]. J. Yan a nd A.M. Karlsson thank the National Science Foundation for financial support under contract DMR-0346664 


\section{References}

[1] M. Bartsch, G. Marci, K. Mull and C. Sick: Advanced Engineering Materials 2 (1999), p. 127.

[2] B. Baufeld, M. Bartsch, S. Dalkilic and M. Heinzelmann: Surface \& Coatings Technology. 200 (2005), p. 1282.

[3] M. Bartsch, B. Bauf eld, S. Dalkilic and M. Heinzelmann: International Journal of Fatigue (2006) in press.

[4] U. Schulz, M. Menzebach, C. Leyens and Y. Q. Yang: Surface \& Coatings Technology 146-147 (2001), p. 117.

[5] A.M. Karlsson, J.W . Hutchinson and A.G. Evans: Materials Science \& Engineering. A351 (2003), p. 244.

[6] J. Rösler, M. Bäker and M. Volgmann: Acta materialia 49 (2001), p. 3659

[7] M. Hernandez, M. Bartsch and A.M. Karlsson, in progress

[8] M.D. Drory and J.W . Hutchinson: Pro ceeding Of the Royal Society London A 452 (1996), p. 2319.

[9] A. Vasinonta and J. Beuth: Engineering Fracture Mechanics 68 (2001), p. 843.

[10] V. Sergo and D. Clarke, Journal of the American Ceramic Society 81 [12] (1998), p. 3237. 